\title{
The Emotionality and Complexity of Public Political Language in Canada's Question Period
}

\author{
Cynthia Whissell ${ }^{1}$ \\ ${ }^{1}$ Psychology Department, Laurentian University, Sudbury, Ontario, Canada \\ Corrspondence: C. Whissell, Psychology Department, Laurentian University, Sudbury, Ontario, P3E 2C6, \\ Canada. E-mail: cwhissell@laurentian.ca
}

Received: August 28, 2012 Accepted: October 19, 2012 Online Published: October 24, 2012

doi:10.5539/ells.v2n4p68 URL: http://dx.doi.org/10.5539/ells.v2n4p68

\begin{abstract}
Purpose: In order to better understand the impression conveyed by the language of public political discourse occurring in highly regulated settings, it was decided to study words used by politicians from four parties in a random sample of 10 Question Periods from Canada's $39^{\text {th }}$ Parliament. Data were downloaded from the Hansard Report. In a quantitative textual approach, the language used by speakers was analyzed in terms of its emotional content and linguistic complexity. Findings: In comparison to everyday English, the language of Question Period was complex and emotionally negative. Members of opposition parties asking questions used more negative and arousing words than government members answering them. Women spoke in more pleasant language than men, and addressed different topics. There were also differences among the opposition parties.
\end{abstract}

Keywords: language, emotion, political discourse, Question Period

\section{Introducation}

\subsection{Public Political Language}

What impressions do Canadians receive from Members' discourse during Parliament's Question Period? This portion of the parliamentary day provides several sound bites for newscasters, and is broadcast in its entirety on television. When Canadians think of "government in action" they are often thinking of politicians asking or answering questions during Question Period. Public documents which were once tediously difficult to access and transcribe are now available at the click of a button on official web sites. Because of this, the style and emotional undertones of language employed during Question Period can be easily assessed. The availability of computer programs which score text automatically also facilitates assessment. This article examines data from the Hansard web site and analyzes the language that Members of Parliament used during the Question Period of Canada's $39^{\text {th }}$ Parliament. Politicians' language is examined at the level of single words, and is scored in terms of its emotional overtones with a relatively objective technique (the DAL or Dictionary of Affect in Language; Whissell, 1994a; 2009). Language complexity is represented by measures of word length, word frequency, and word concreteness. Comparisons are made between the language of government and opposition parties, and also that used by men and women Members of Parliament.

\subsection{Question Period}

Formally titled "Oral Questions," the Canadian Question Period is 45 minutes long and is taken up during each parliamentary day in the House of Commons (Marleau \& Montpetit, 2000, pp. 416-433). This period is similar in intent and practice to the British Question Time whose parallels are found in Australia, India, and New Zealand. During Question Period, members of opposition parties (and occasionally backbenchers from the governing party) address questions to the Speaker. Members of the government respond to the questions, which are answered by the Prime Minister himself, his Ministers, or their representatives. Question Period embodies "the right to seek information from the Ministry of the day and the right to hold that Ministry accountable" (Marleau \& Montpetit, 2000, p. 416): because of this, it tends to be confrontational. It has a thrust-and-parry style, and is often covered by the media because of its rather exciting tone. Although the main work of the government does not take place during Question Period, the concerns of government and of opposition parties are frequently addressed there, allowing for considerable insight into the ongoing business of Parliament (Marleau \& Montpetit, 2000, p. 416). Question Period is regularly broadcast on CPAC, the parliamentary channel, and on TVO, the 
Ontario public television channel.

Question Period is not as unregulated as it may seem to the casual observer. Questions are allowed in proportion to party representation in Parliament and party leaders submit a list of questioners to the Speaker. Time taken to ask and answer questions is limited. Both questions and answers must be addressed to the Speaker. As a matter of parliamentary procedure, members are not allowed to address one another directly. A degree of politeness in language is enforced. For example, no Member may call another a liar (at any time, including Question Period). Although they are referring to the British political system, de Ayala (2001) and Harris (2001) provide an interesting and apt discussion of the balance between required political politeness and adversarial political discourse with respect to Question Time. According to these authors, the aim of most Members of the Opposition who ask questions is to threaten or attack the public face of the governing party: while doing this, they are constrained by House rules with respect to polite discourse. Here is a sample interchange between the leader of the Liberal party and the Prime Minister (from Question Period, May 8, 2006):

Hon. Bill Graham (Leader of the Opposition, Lib.):

Mr. Speaker, Canadians are the envy of the world because we live in a country governed by laws, laws that are consistently and fairly applied by a competent, capable and independent judiciary.

For years the Conservatives, who do not like our democratically adopted laws, have been attacking our judges, but this weekend the member for Saskatoon-Wanuskewin went too far. "Ridiculous," he said, "the judges think they are divine", and accused the Chief Justice of the Supreme Court of believing she has mystical powers.

What does the Prime Minister intend to do to stop these absurd and politically motivated attacks on our Canadian judiciary?

Right Hon. Stephen Harper (Prime Minister, CPC):

Mr. Speaker, the hon. Leader of the Opposition should be aware that the member for Saskatoon -Wanuskewin has already said that these are his own personal views and that they do not represent the position of the government. They certainly do not represent the position of the government.

The "thrust" of the question from the then-leader of the Liberal party is an accusation of name-calling. The Prime Minister "parries" by claiming that the putative name-caller was speaking on his own behalf, not that of the government. Both question and answer are directed to the Speaker and include the address "hon." (honorable), which is an obligatory politeness. The affectively loaded nature of the discourse during Question Period can be noted in the questioner's use of words such as "attacking" and "absurd" and in the rather bombastic introduction to the question. The Speaker of the House guides the flow of Question Period and intervenes to maintain order when discourse threatens to become too heated, or when Members of Parliament other than the one posing or answering a question create too much interference (Marleau \& Montpetit, 2000, p. 421).

\subsection{The Hansard Report}

The Hansard Report and its name trace back to the British system for keeping a verbatim diary of parliamentary proceedings. Hansard was the original publisher of the diary. Canada's Hansard is a transcript of the words spoken in Parliament, officially called its Debates (Marleau \& Montpetit, 2000, pp. 965-969). It has been published since the time of the first Canadian Prime Minister, Sir John A. Macdonald, who was one of its staunch supporters (Ward, 1980, p. 136). Canadians speak both French and English in Parliament and there are two complete Hansard Reports, one in either language. The reports are transcribed from taped sessions of Parliament and edited for clarity and accuracy ${ }^{1}$. Once transcripts have been produced and edited, Hansard Reports become electronically available to the general public ${ }^{2}$. The history of parliamentary reporting in Canada and of the Hansard Report in pre-computer years is outlined by Ward (1980).

De Ayala (2001, p. 51) and others rightly urge caution in the use of oral materials that are transferred to writing. Factors of prosody (e.g., intonation, emphasis) are completely lost in a transcription, as are hesitations, reduplications of syllables (e.g., par-par-parliament) and intended punctuations. Cat-calls and/or cheers of praise from Members of Parliament not officially speaking at any moment are recorded only occasionally and symbolically (e.g., "Some hon. Members: Hear, hear!" which signals approbation or "Some hon. Members: Oh, oh!" which signals disapproval). At the level which is important to this research, however, the Hansard Report can be considered a reliable source. The report aims to correctly record all words spoken during a session by a recognized Member, and the analyses described here are based on words rather than prosody, punctuation, or speech abnormalities. 


\subsection{The Emotional Meaning of Words}

The Dictionary of Affect in Language or DAL was developed to quantify the emotional meaning of language (Whissell, 2009). Natural language - i.e. normally spoken or written English - is made up of words, each of which has a variety of meanings. Individual words are less like monoliths and more like onions in the construction of their meaning, with layer upon layer of meaning (some layers shared, some idiosyncratic) being associated with every word. After studying semantics for many years, Osgood (1969) noted that besides conveying a denotative or literal meaning, words also convey a set of feelings. These feelings are implicitly rather than explicitly communicated, so Osgood referred to them as instances of connotative meaning. For example, the word "attack" carries a denotative meaning ("to set upon forcefully," as per Webster's $9^{\text {th }}$ New Collegiate Dictionary) and at least two connotative meanings (according to the DAL, attacks are unpleasant rather than pleasant and active rather than passive). Whenever the word "attack" appears in a sample of natural language such as a parliamentary debate, the listener or reader receives impressions based on both dictionary and DAL meanings.

The DAL includes ratings provided by volunteers for 8742 words along the two stable bipolar and orthogonal dimensions of Pleasantness and Activation (Russell, 1978). Volunteers (both men and women, primarily university students) were asked to look at single words and rate them in terms of the dimensions indicated. The average of their ratings was assigned to the word. Rather than providing denotative definitions as Webster's dictionary does, the DAL provides numbers that represent how Pleasant people think a word is and how Active they believe it to be. For example, in the DAL the word "attack" has scores of 1.00 for Pleasantness (the minimum on a scale of 1-3), and 2.57 for Activation (close to the maximum). "Attack" is, as suggested above, unpleasant and active. Because it was constructed from natural language samples, the DAL generally matches $90 \%$ of the words in such samples. Words with extreme emotional implications belong to one of eight extreme DAL categories (Table 1). The extreme categories used here were non-overlapping, and the decision to include a word in a category depended only on the word's DAL scores. Examples in Table 1 came from Question Period: they fall at least one standard deviation away from the mean in the appropriate direction in a two-dimensional space defined by Activation and Pleasantness.

The eight categories represent all possible combinations of three levels of the Pleasantness (Unpleasant, Average, Pleasant) and the Activation dimension (Passive, Average, Active), with words that are within one standard deviation of the mean on both dimensions being excluded from analysis because they are not emotionally informative. In order to facilitate reference to the eight categories, each is assigned a code name that summarizes its emotional tone. For example, the code name "Sad" represents the category of Unpleasant/Passive words: this category includes words such as "dead" and "deficit." Because of its scores, the word "attack" belongs to the Unpleasant/Active or "Nasty" category in the lower right of Table 1, which includes words such as "dangerous" and "shooting." In addition to the two affective dimensions of Pleasantness and Activation, the DAL includes ratings for a dimension which is cognitive. This dimension, Imagery, represents the degree to which a word is easily envisioned or Concrete: words rated as high in Imagery tend to be Concrete (Paivio, 2007, p. 46). Words such as "doctor" and "gun" are Concrete and high in Imagery while words such as "adverse" and "ideology" are Abstract and difficult to picture (Table 1).

DAL scoring has been fruitfully applied to many different samples of natural English including the Bible (Whissell, 2004c) and titles of journal articles (Whissell, 2004b). It has also been employed in analyses of political discourse (Sigelman \& Whissell, 2002; Whissell \& Sigelman, 2001). Entire language samples of various kinds, such as all the words spoken during Question Period, can be characterized by the proportion of their words which fall into various DAL categories.

Imagery is, in fact, a measure of language complexity. Simple language is high in imagery while complex language contains many abstract words that cannot be easily envisioned (Whissell, 2004a). Additional commonly accepted measures of complexity are word length and word frequency (Whissell, 2004a). Word length is a straightforward measure based on number of letters and word frequency can be obtained in comparison to a normative corpus of everyday English (such as Whissell, 1998b). Longer words and rarer words are more complex.

\subsection{Predictions of the Research}

Several predictions were made addressing the character of political language, the thrust-and-parry nature of Question Period as well as party differences, and gender differences. 
Table 1. Categories of extreme emotional and imaged words and samples from Question Period belonging to each category

\begin{tabular}{lll}
\hline $\begin{array}{c}\text { Pleasant/Passive } \\
\text { "Soft" }\end{array}$ & $\begin{array}{c}\text { Pleasant/Average } \\
\text { "Pleasant" }\end{array}$ & $\begin{array}{c}\text { Pleasant/Active } \\
\text { "Cheerful" }\end{array}$ \\
\hline Beautiful & Agreements & Approved \\
Forests & Family & Children \\
Generous & Opportunity & Freedom \\
Merits & Reasonable & Justice \\
Recommend & Satisfactory & Laughing \\
Sentiment & Valid & Reassure \\
Warmth & Young & Victory \\
\hline Average/Passive & Average/Average & Average/Active \\
"Passive" & "Unemotional" & "Active" \\
& & Action \\
Associates & Competition \\
Calm & Demanded \\
Hesitate & (not & Leadership \\
Normal & analyzed) & Persistence \\
Solemn & & Soldiers \\
Wooden & & \\
\hline Unpleasant/Passive & Unpleasant/Average & Unpleasant/Active \\
"Sad" & "Unpleasant" & "Nasty" \\
& Awful & Abuse \\
Absence & Barriers & Arrest \\
Dead & Failure & Dangerous \\
Deficit & Misfortune & Forcing \\
Ignorance & Rejected & Shooting \\
Minority & Tragedy & Victims \\
Sad & Unemployment & Worry \\
Welfare & & \\
& &
\end{tabular}

Imagery Dimension:

High Imagery "Concrete": Battle, City, Doctor, Family, Gun, Officer, People

Low Imagery "Abstract”: Adverse, Conversation, Guaranteed, Ideology, Merits, Prosperity

Question Period is adversarial in nature. Questioners often incorporate an accusatory tone in their thrusts, while responders attempt to parry threats to their public face (de Ayala, 2001; Harris, 2001). Because of this, it was expected (1a) that the overall language of Question Period would be confrontational or emotionally negative and (1b) that the language of questioners (opposition party members) would be more negative and forceful in tone, while that of responders (government members) which would be more positive or more placating, as speakers attempt to defray various threats. Confrontational language is identified by the presence of relatively more Active and/or Nasty, and/or Unpleasant words and placating language by the presence of more positively-toned words. Because politics is a public process of considerable complexity, it was predicted (1c) that the general language of Question Period would be complex, including relatively few Concrete words and few short and common ones as well. In a non-directional prediction, it was hypothesized that (1d) in addition to differences between government and opposition speakers there would be differences in language patterns among speakers from different opposition parties.

Language directed at women is more pleasant or positive in tone than that directed at men (for example, in novels and in advertisements: Whissell, 1994b; Whissell \& McCall, 1997). As well, women tend to score higher on the pleasant dimensions of personality tests (Feingold, 1994; Whissell 1996). In view of these findings, it was predicted (2a) that women's speeches in Question Period would contain more Pleasant and/or Cheerful and/or Soft types of words than men's. As well, girls have an early linguistic advantage over boys, and women tend to have higher scores on vocabulary-based tests of mental ability than men (Johnson \& Bouchard, 2007). On this basis, it was predicted (2b) that the language used by women would be more complex than that used by men. It has been reported that women in politics tend to concern themselves with more "feminine" or "nurturing" topics such as the health and welfare of others. MacIvor (1996, pp. 280-281) refers to "the concentration of women in 
particular areas of policy" and to the existence of "pink portfolios" that are assigned to women ministers. It was therefore predicted (2c) that there would be a difference between the types of topics addressed by men and women Members in the direction noted by MacIvor.

\section{Method}

\subsection{Materials Sampled}

In December, 2006, there were 97 days of English Hansard Reports available for the Canadian (House of Commons) $39^{\text {th }}$ Parliament. Ten days were chosen at random (April 28, May 8, 9, and 17, June 5, September 19 and 26, October 18, November 7, and December 12) and the contents of Question Period were copied into a data file for these days. Points of order and recognitions of presence (e.g., the presence of visiting politicians) which occur at the end of Question Period were removed. Each speaker was coded in terms of party of allegiance and note was taken as to whether the speaker was a woman or a man. The Speaker of the House was coded separately, and his dialogue, which was minimal, was omitted. Formulaic descriptions of background vocalizations (such as $\mathrm{Oh}$, oh!) were also excised because these are approximations which were not spoken by recognized speakers. The ten days contained an average of 83 speeches per day, with an average of 74 words per speech (a total of 61,487 words). These data suggest a rapid rate of delivery: 137 words per minute -more than two per second for the 45 minutes of each Question Period. Because of the turn-taking nature of Question Period, speeches were roughly equally divided between opposition questioners and government responders.

\subsection{Scoring Word Emotionality and Complexity}

All words in the 10 Question Periods were matched, one at a time, to the DAL with the help of a computer program. If a match was found, the DAL values for the matched word (Pleasantness, Activation, and Imagery) were imported into a data file. The DAL matching rate was $91 \%$. Values for the DAL dimensions were used to determine whether a word belonged to one of the eight extreme emotional categories described in Table 1, and whether it was a Concrete word (with a score more than one standard deviation above the mean for Imagery). Each of these categories was represented by a dummy binary variable (no/yes or 0,1 , with a score of 1 indicating membership).

The average length of words in natural English is slightly above four letters (Whissell, 1998b) and a relative small number of common words accounts for a large proportion of tokens used in natural English. Words from Question Period were therefore scored in terms of length (four or fewer letters versus five or more letters) and in terms of whether they were or were not common words (those with a frequency of more than 300 per million in Whissell, 1998b, were considered common).

At the end of the scoring process, which was accomplished by a computer program, there were 11 binary (no/yes or 0,1$)$ measures associated with each individual word type (Table 2). These were its membership in the eight extreme emotional categories of Table 1, its status as a Concrete word, its status as a short word and its status as a common word.

\section{Results}

\subsection{Overall Findings for Emotion and Complexity}

Percentage usage scores varied widely across categories. In order to make data more interpretable, Usage in Table 2 is expressed as a "percentage of normal for everyday English," with "normal" usage levels being dictated by the widely sampled corpus of 348,000 words representing everyday English (Whissell, 1998b). Values close to $100 \%$ indicate average everyday usage, values well below 100 below-average usage, and values well above it above-average usage. For example, if a text of a given size in everyday English includes 50 Active words, and a comparative text of equal length 60 , the second text has $120 \%$ of normal ((60/50) x100) Active words. Groups of Members are described in terms of their percentage of normal use of the 11 types of words. The usage for all categories of words was compared to everyday English with the help of $z$ tests for proportions. Percentages for all speakers on all ten days appear in the first data column of Table 2. All speakers used fewer than normal Pleasant (84\%), Cheerful (87\%), and Soft (58\%) words, and more than normal Active (145\%) and Nasty $(108 \%)$ words. The most pronounced emotional effects were associated with the avoidance of Soft words ( $42 \%$ below normal) and the inclusion of Active words ( $45 \%$ above normal). Because the language of Question Period included significantly fewer than $100 \%$ common (94\%), Concrete (84\%), and short (94\%) words it was more complex than everyday English. 
Table 2. Percentage of normal usage ${ }^{1}$ for all 14 word types for the whole groupsand various subgroups

\begin{tabular}{|c|c|c|c|c|c|}
\hline Type of Word & $\mathrm{All}^{2}$ & Men & Women & Gvrnmnt & Opposition \\
\hline $\begin{array}{l}\text { Emotions } \\
\text { Pleasant }\end{array}$ & $84 *$ & & & $101 *$ & \\
\hline Cheerful & $87 *$ & $\overline{83}$ & $97 *$ & $\begin{array}{l}101^{*} \\
90^{*}\end{array}$ & $\begin{array}{l}53 \\
83\end{array}$ \\
\hline Soft & $58^{*}$ & 54 & $66^{*}$ & $63^{*}$ & 52 \\
\hline Active & $145^{*}$ & - & - & 135 & $153^{*}$ \\
\hline Nasty & $108^{*}$ & - & - & 100 & $114^{*}$ \\
\hline Unpleasant & $85^{*}$ & & & & \\
\hline $\mathrm{Sad}$ & $97^{*}$ & $99 *$ & 90 & 90 & $105^{*}$ \\
\hline Passive & $110^{*}$ & - & - & 107 & $113^{*}$ \\
\hline Complexity & & & & & \\
\hline $\begin{array}{l}\text { Common } \\
\text { Concrete }\end{array}$ & $\begin{array}{l}94 * \\
84^{*}\end{array}$ & $\begin{array}{c}- \\
-\end{array}$ & - & $\begin{array}{l}98^{\circ} \\
71\end{array}$ & $\begin{array}{l}91 \\
95 *\end{array}$ \\
\hline Short & $94 *$ & $95^{*}$ & 91 & $96^{*}$ & 91 \\
\hline $\begin{array}{l}\text { Number } \\
\text { of words }\end{array}$ & 61.487 & 47.908 & 13.579 & 27.987 & 30,303 \\
\hline
\end{tabular}

${ }^{1}$ Percentages are reported in comparison to a broadly sampled corpus of everyday English (Whissell, 1998b).

${ }^{2}$ All=entire group, Men=male speakers, Women=female speakers, Gvrnmnt=individuals answering for the government, Opposition=speakers from any opposition party.

* For the first column of numbers, an asterisk indicates a significant difference $(\mathrm{p}<.05)$ of any entry from normative data (norm=100\%); for the remaining pairs of columns the significantly higher $(p<.05)$ of two percentages is starred. Percentages not associated with significant chi squared values are omitted (-) and could be represented by values in the first column of numbers.

\subsection{Comparisons among Groups of Speakers}

The results described in this section are based on contingency chi squared analyses where binary variables (such as common word - yes or no) were cross-tabulated with group membership variables (such as party government or opposition). Table 2 summarizes the results of several such analyses. Overall, women speakers during Question Period used more Cheerful and Soft words than men speakers (Table 2), although both groups used fewer such words than are characteristically encountered in everyday English. Women also used fewer Sad words than men. Women used fewer short words than men, suggesting a greater complexity of language. No significant differences were observed for the remaining nine variables.

Although there were several significant differences between men and women speakers, these were rarer than significant differences between government and opposition speakers (Table 2). Opposition speakers attempting to threaten the political face of government members used more Active and Nasty words while Government speakers attempting to deflect verbal attacks used more Pleasant, Cheerful, and Soft words. Although all the language of Question Period was negatively toned, the language of opposition questioners was more emotionally negative than that of government responders.

The three opposition parties (Liberal, Bloc Quebecois, New Democratic) were compared to one another in terms of their use of the 11 types of words described in Table 2. Proportionally more Active words were spoken by members of the NDP (175\% of normal), followed by members of the Bloc (160\%) and members of the Liberal party $(143 \%)$. Proportionally more Soft words were spoken by members of the Bloc Quebecois $(59 \%$ versus $49 \%$ for each of the other two parties). Members of the Bloc also employed fewer Concrete words ( $84 \%$ versus $98 \%$ and $100 \%$ ).

The Hansard Report lists the topic under which all questions were asked and answered during Question Period. All topics addressed on at least two separate days and all those including at least 10 speeches on any single day were compared in terms of the speaker's gender. Women spoke proportionally more often on nurture-related topics such as aid, minority affairs, worker benefits, and the status of women. Men spoke proportionally more often on issues such as public safety, fisheries, and national defense. Statistically significant differences were limited to the most frequently discussed topics and to those where gender differences were extreme.

\section{Discussion}

\subsection{Support for the Predictions of the Research}

In spite of the tightly regulated nature of Question Period, many group differences in emotionality and language complexity were noted. Opposition and government parties did not use the same language, and neither did men 
and women Members of Parliament.

In tune with the first prediction (1a), Question Period may indeed be labeled as adversarial in nature because it contains relative few Pleasant, Cheerful, and Soft words, and relatively many Active and Nasty ones in comparison to everyday English. Regulated attempts at polite discourse might account for the lower-than-normal use of Unpleasant words and the higher-than-normal use of Passive ones that were also observed. The language (1b) used by opposition members asking questions contained more Active and more Nasty words than the language used by members of the government answering them. As well, the language of members of the government attempting to parry opposition thrusts included more Pleasant, Cheerful, and Soft words and many more first person pronouns.

The overall language of Question Period was, as predicted in (1c), relatively complex. It contained fewer common, fewer short, and fewer Concrete words than the normative sample. In comparisons involving subgroups, government speakers' words were more frequently common and short while opposition speakers' words were more often Concrete. This may be the outcome of the mounting of specific (Concrete) attacks that are countered with relatively abstract generalities. As well, there were several differences noted among opposition parties in patterns of language use (1d).

As predicted (2a), words spoken by women were more positive in emotional tone than those spoken by men: this difference was evident for Cheerful and Soft words, which were used at higher rates by women. The prediction that women would use more complex language than men (2b) was partly supported: men used more short words than women. As well, the bias observed in earlier research and embodied in hypothesis (2c) still exists with respect to the topics discussed by women during Question Period. Women speakers evinced a greater preoccupation with nurturing and helpful ("pink") matters. In parallel there is evidence of a greater preoccupation with topics of force and economics in the discourse of men. It bears mentioning that topic choices could be the result of Members' legitimate preferences as well as role constraints.

\subsection{Alternative Approaches to the Same Materials}

The approach taken to parliamentary discourse in this study was quantitative and textual: it relied exclusively on the vocabularies employed by different speakers. Alternative approaches include critical discourse analysis (van Dijk, 1993) which has a sociopolitical framework with an emphasis on the expression of challenge and dominance. Within such an analysis, access to discourse and rule-breaking within discourse both reflect power or dominance (pp. 257, 263). Question Period is organized in a manner that minimizes differences in access (questioners and responders are granted equal time) and rule-breaking (rules of polite discourse are strictly enforced). Measures of vocabulary can therefore be employed, as they were here, to highlight differences among groups in highly regulates settings.

Fairclough (1992) has argued that textual analysis (which focuses on wording) and discourse analysis (which is intertextual), are complementary approaches to texts (p. 194). Many predictions of this research were based on qualitative studies of political discourse. In future research, the quantitative measures employed here might be used in conjunction with discourse analysis in a form of triangulation (Fairclough, 1992) because bringing a variety of viewpoints to bear ultimately promotes a more accurate "reading" of public political language.

\section{Conclusions}

Canadians exposed to Question Period will be left with an impression of combativeness (opposition questions), defensiveness (government answers) and complexity (language as a whole). They will notice differences in the language of male (tougher language) and female (softer language) speakers, which accord with differences in the topics addressed by the two groups. Viewers will also discern a distinctive flavor in the language of each of the three parties in opposition (e.g., high activation for the Liberals, high abstraction for the Bloc).

\section{References}

De Ayala, S. P. (2001). FTAs and Erskine May: Conflicting needs? - Politeness in Question Time. Journal of Pragmatics, 33, 143-169. http://dx.doi.org/10.1016/S0378-2166(00)00002-3

Fairclough, N. (1992). Discourse and text: linguistic and intertextual analysis within discourse analysis. Discourse \& Society, 1992, 3, 193-217. http://dx.doi.org/10.1177/0957926592003002004

Feingold, A. (1994). Gender differences in personality: A meta-analysis. Psychological Bulletin, 116, 429-456. http://dx.doi.org/10.1037/0033-2909.116.3.429

Harris, S. (2001). Being politically impolite: Extending politeness theory to adversarial political discourse. Discourse and Society, 12, 451-472. http://dx.doi.org/10.1177/0957926501012004003 
Johnson, W., \& Bouchard, T. J. Jr. (2007). Sex differences in mental abilities: $g$ masks dimensions on which they lie. Intelligence, 35, 23-39. http://dx.doi.org/10.1016/j.intell.2006.03.012

MacIvor, H. (1996). Women and politics in Canada. Peterborough, Ontario: Broadview Press.

Marleau, R., \& Montpetit, C. (2000). House of Commons procedure and practice. Toronto, Ontario: McGraw-Hill.

Osgood, C. E. (1969). On the whys and wherefores of E, P, and A. Journal of Personality and Social Psychology, 12, 194-190. http://dx.doi.org/10.1037/h0027715

Paivio, A. (2007). Mind and its evolution: A dual coding theoretical approach. Mahwah, NJ: Lawrence Erlbaum Associates.

Russell, J. A. (1978). Evidence of convergent validity on the dimensions of affect. Journal of Personality and Social Psychology, 36, 1152-1168. http://dx.doi.org/10.1037/0022-3514.36.10.1152

Sigelman, L., \& Whissell, C. (2002). "The great communicator" and "the great talker" on the ratio: Projecting $\begin{array}{llll}\text { presidential personas. Presidential Studies } & \text { Quarterly, 32, }\end{array}$ http://dx.doi.org/10.1111/j.1741-5705.2002.tb00007.x

Van Dijk, T. A. (1993). Principles of critical discourse analysis. Discourse \& Society, 4, 249-283. http://dx.doi.org/10.1177/0957926593004002006

Ward J. (1980). The Hansard chronicles: celebrating 100 years of Hansard in Canada. Ottawa, Ontario: Deneau \& Greenberg.

Whissell, C. (1994a). A computer program for the objective analysis of style and emotional connotations of prose: Hemingway, Galsworthy, and Faulkner compared. Perceptual and Motor Skills, 79, 815-824. http://dx.doi.org/10.2466/pms.1994.79.2.815

Whissell, C. (1994b). Objective analysis of text: I A comparison of adventure and romance novels. Perceptual and Motor Skills, 79, 1567-1570. http://dx.doi.org/10.2466/pms.1994.79.3f.1567

Whissell, C. (1996). Predicting the size and direction of sex differences in measures of emotion and personality. Genetic, Social, \& General Monographs, 122, 253-284.

Whissell, C. (1998a). Linguistic, emotional, and content analyses of sexually explicit scenes in popular fiction. Canadian Journal of Human Sexuality, 7, 147-159.

Whissell, C. (1998b). A parsimonious technique for the analysis of word-use patterns in English texts and transcripts. Perceptual and Motor Skills, 86, 595-613. http://dx.doi.org/10.2466/pms.1998.86.2.595

Whissell, C. (2003). Readers' opinions of romantic poetry are consistent with emotional measures based on the Dictionary of Affect in Language. Perceptual and Motor Skills, 96, 990-992.

Whissell, C. (2004a). Poetic emotion and poetic style: the 100 poems most frequently included in anthologies and the work of Emily Dickinson. Empirical Studies of the Arts, 22, 55-74. http://dx.doi.org/10.2190/FWGA-M9DB-P9D4-11X6

Whissell, C. (2004b). Titles of articles published in the journal Psychological Reports: Changes in language, emotion, and imagery over time. Psychological Reports, 94, 807-813. http://dx.doi.org/10.2466/pr0.94.3.807-813

Whissell, C. (2004c). Using computer-scored measures of emotion and style to discriminate among disputed and undisputed Pauline and non-Pauline epistles. Perceptual and Motor Skills, 98, 1117-1125. http://dx.doi.org/10.2466/pms.98.3c.1117-1125

Whissell, C. (2006). Serial publication and the emotional associations of words in Dickens' David Copperfield. Psychological Reports, 99, 751-761. http://dx.doi.org/10.2466/PR0.99.3.751-761

Whissell, C. (2009). Using the revised Dictionary of Affect in Language to quantify the emotional undertones of samples of natural language. Psychological Reports, 105, 509-521. http://dx.doi.org/10.2466/pr0.105.2.509-521

Whissell, C., \& McCall, L. (1997). Pleasantness, activation, and sex differences in advertising. Psychological Reports, 81, 355-367. http://dx.doi.org/10.2466/pr0.1997.81.2.355

Whissell, C., \& Sigelman, L. (2001). The times and the man as predictors of emotion and style in the inaugural addresses of U.S. presidents. Computers and the Humanities, 35, 255-272. 
http://dx.doi.org/10.1023/A:1017569003556

\section{Notes}

Note 1. A description of the process for producing Hansard Reports can be found at: http://www.hansard.ca/editors.html

Note 2. The Hansard reports themselves can be accessed at: www.parl.gc.ca/common/chamber_house_debates.asp?language $=\mathrm{e}$ 